\title{
Metais Pesados em Macroalgas Marinhas na Costa Norte do ESTADO DO RIO DE JANEIRO, BRASIL.
}

\author{
ANDRÉ LUIS DOS SANTOS MACHADO \\ ALEXANDRE GOMES FERREIRA \\ ILANA ROSENTAL ZALMON
}

Universidade Estadual do Norte Fluminense, Centro de Biociências e Biotecnologia, Laboratório de Ciências Ambientais.

\begin{abstract}
RESUMO
Este trabalho teve como principal objetivo determinar a concentração dos metais Cr, $\mathrm{Cu}, \mathrm{Fe}, \mathrm{Mn}$ e Zn na clorófita Ulva fasciata e na rodófita Gymnogongrus sp coletadas nas praias de Barra do Furado (22 $00^{\circ}$ S; $41^{\circ} 00^{\prime}$ W) e Ponta do Retiro ( $21^{\circ} 29^{\prime}$ S, $41^{\circ} 59^{\prime}$ W), costa norte do Estado do Rio de Janeiro. A rodófita Gymnogongrus sp apresentou uma alta capacidade para acumular os metais analizados em relação a $U$. fasciata em ambas as praias. As concentrações de $\mathrm{Cr}$, $\mathrm{Cu}$ e $\mathrm{Mn}$ foram mais elevadas em Barra do Furado, quando comparadas com Ponta do Retiro, contudo, Fe e Zn mostraram valores superiores em Ponta do Retiro. Em relação a variação temporal, apenas as concentrações de $\mathrm{Cr}$ apresentaram diferenças significativas $(\mathrm{p}<0.05)$ ao longo do ano em ambas as algas e áreas de estudo. As maiores concentrações de Fe e Mn foram observadas de fevereiro 1999 a maio 1999, enquanto valores mais baixos de Cr e Zn foram observados em outubro 1998 e novembro 1998. Os resultados indicam a macroalga Gymnogongrus sp para o biomonitoramento de metais pesados, por ser mais abundante e apresentar maiores concentrações de metais pesados em relação a Ulva fasciata.
\end{abstract}

Palavras chave: Metais; Macroalgas; Rio de Janeiro; Bioindicadores; Entrada Continental.

\begin{abstract}
The main objective of this work was to determine the metal concentrations $(\mathrm{Cr}, \mathrm{Cu}$, $\mathrm{Fe}, \mathrm{Mn}$ and $\mathrm{Zn}$ ) in the chlorophyta Ulva fasciata and in the rhodophyta Gymnogongrus sp collected at Barra do Furado (22 ${ }^{\circ} 00^{\prime}$ S; $41^{\circ} 00^{\prime}$ W) and Ponta do Retiro (21 $21^{\circ}$ ' S, $41^{\circ} 59^{\prime}$ W) beaches, northern coast of Rio de Janeiro. The rhodophyta Gymnogongrus sp showed higher capacity to accumulate the analyzed metals compared to $U$. fasciata at both beaches. The concentrations of $\mathrm{Cr}, \mathrm{Cu}$ and $\mathrm{Mn}$ were higher at Barra do Furado, when compared with Ponta do Retiro. However, Fe and Zn showed higher values on Ponta do Retiro beach. In relation to temporal variation, $\mathrm{Cr}$ concentrations showed significant differences $(\mathrm{p}<0.05)$ along the year in both algae and studied areas. Highest Fe and Mn concentrations were observed from February 1999 to May 1999, while the lowest Cr and Zn values were found on Octuber 1998 and November 1998. The results indicate that the macroalgae Gymnogongrus sp as the best heavy metal biomonitoring tool since it is more abundant and showed higher metal concentrations in relation to Ulva fasciata.
\end{abstract}

Key words: Metals; Macroalgae; Rio de Janeiro; Bioindicators; Continental runoff. 


\section{INTRODUÇÃO}

O Brasil possui uma zona costeira com aproximadamente $7.700 \mathrm{~km}$ de extensão, composta por uma grande variedade de ecossistemas (ex. manguezais e estuários) e importantes formações oceânicas (ex. arquipélagos e atóis). Nos últimos anos, importantes estudos sistemáticos de biologia, química e física (ex. Projeto REVIZEE - Recursos Vivos da Zona Econômica Exclusiva; Projeto MoMAM - Monitoramento do Meio Ambiente Marinho (CARVALHO et al, 2001) vêm sendo desenvolvidos, permitindo subsidiar relevantes tomadas de decisão ao longo de seu mar territorial, bem como para a conservação de seus recursos.

O litoral norte do Estado do Rio de Janeiro vem sendo incluído, em programas/propostas de monitoramento de impacto ambiental, principalmente em função da intensificação das atividades petrolíferas na Bacia de Campos (SANTOS, 2001). Estes estudos visam, entre outros fins, contemplar possíveis alterações nos ciclos biogeoquímicos de metais pesados, visto que os rejeitos das plataformas são enriquecidos nestes elementos quando comparados com as águas de superfície. Desta forma, muitos destes trabalhos referem-se aos levantamentos preliminares da dispersão destes poluentes em todo o litoral do Estado do Rio de Janeiro (MINISTÉRIO DA MARINHA DO BRASIL, 1997).

Os objetivos deste estudo foram: i) determinar as concen-trações de $\mathrm{Cr}, \mathrm{Cu}, \mathrm{Fe}, \mathrm{Mn}$, e Zn na clorófita Ulva fasciata e na rodófita Gymnogongrus sp coletadas nas praias de Barra do Furado e Ponta do Retiro (Fig. 1); ii) caracterizar as variações temporais dos metais em cada local de coleta utilizando macroalgas como espécies biomonitoras; iii) identificar variações espaciais nas concentrações bioacumuladas desses metais entre os locais de coleta e iv) comparar a capacidade de acumulação de metais pesados entre as duas espécies de macroalgas analisadas.

\section{MATERIAL E MÉTODOS}

As algas foram coletadas, a cada 45 dias, no período de julho 1998 a maio 1999. Todas as amostras foram obtidas na região do mesolitoral em cada uma das praias: Ponta do Retiro, caracterizada pela presença de concreções ferruginosas e, Barra do Furado, predominantemente estuarina em função da saída do canal das Flechas, responsável pela drenagem das águas da lagoa Feia. No laboratório as amostras foram lavadas com água do local para retirada de epífitas e outros organismos associados, bem como, dos sedimentos depositados na superfície foliar. Após esta etapa, as algas foram secas em estufa a $80^{\circ} \mathrm{C}$ por $48 \mathrm{~h}$. Em seguida, o material foi homogeneizado e separado em alíquotas de aproximadamente $1,00 \mathrm{~g}$ que foram solubilizadas com $10 \mathrm{ml}$ de ácido nítrico $\left(\mathrm{HNO}_{3}\right)$ concentrado. Após a solubilização, as amostras foram aquecidas a $110^{\circ} \mathrm{C}$ até que todo o ácido evaporasse (KAREZ et al, 1994). Todos os extratos foram filtrados e tiveram o volume aferido a $20 \mathrm{~mL}$ de $\mathrm{HNO}_{3} 0,5 \mathrm{~N}$.

As concentrações de $\mathrm{Cr}, \mathrm{Cu}, \mathrm{Fe}, \mathrm{Mn}$, e $\mathrm{Zn}$ foram determinadas por espectrofotometria de emissão atômica com plasma induzido (Varian modelo Liberty Series II). Foi utilizado material certificado de referência (DORM 1 - Marine Analytical Chemistry Standards Programs/Canadá) com o objetivo de avaliar a reprodutibilidade do método de digestão. O percentual de recuperação dos metais foi de $84(\mathrm{Cr}), 102(\mathrm{Cu}), 99(\mathrm{Fe}), 87(\mathrm{Mn})$ e $88(\mathrm{Zn}) \%$.

Foram empregados os testes estatísticos não paramétricos de Mann-Withney (Teste $U$ ) para verificação de diferenças nas concentrações dos metais entre os locais de coleta, e de Kruskal-Wallis para análise de variância temporal em cada praia amostrada. 


\section{RESULTADOS}

A tabela I apresenta uma comparação dos valores médios das concentrações de $\mathrm{Cr}, \mathrm{Cu}, \mathrm{Fe}, \mathrm{Mn}$ e Zn nas macroalgas estudadas e em espécies coletadas em outras áreas tropicais.

No presente estudo, em média, a concentração de todos os metais foi maior na rodófita do que na clorófita (Fig.. 2). Quanto aos locais de coleta, podemos observar que Gymnogongrus sp apresentou concentrações superiores de Cr, Cu e Mn na praia de Barra do Furado e de Fe e Zn na praia de Ponta do Retiro (Figura 2). Para esta mesma espécie, $\mathrm{Cu}$ e $\mathrm{Mn}$ foram os únicos metais cujas concentrações variaram significativamente $(\mathrm{p}<0,05)$ entre os locais de coleta. $U$. fasciata apresentou maiores concentrações de $\mathrm{Cr}$ e Zn em Barra do Furado e $\mathrm{Cu}$, Fe e Mn na praia de Ponta do Retiro (Fig. 2). A análise estatística revelou que a concentração de todos os metais para esta clorófita, diferiu significativamente $(p \leq 0,05)$ entre as áreas de estudo.

Com relação a variação temporal (Fig. 3a, 3b e 3c), a concentração de $\mathrm{Cr}$ variou significativamente em ambas as macroalgas nas duas praias. Entre Outubro 1998 e Fevereiro 1999 foram determinadas as menores concentrações deste metal na clorófita e na rodófita $\left(<0,1 \mu \mathrm{g} \cdot \mathrm{g}^{-1)}\right.$ (Fig. 3a).

A concentração de manganês em Gymnogongrus sp variou significativamente $(\mathrm{p}<0,05)$ em ambas as praias (Fig. 3b). Em Barra do Furado, foram determinadas concentrações elevadas deste metal ao longo de todo período amostral, com uma nítida tendência de acúmulo no final do verão. A mesma tendência não foi observada para $U$. fasciata, apesar da significativa variação de concentração deste metal em Barra do Furado.

Em Ponta do Retiro, a concentração de Fe em $U$. fasciata variou significativamente $(\mathrm{p}<0,05)$. O valor mínimo determinado foi de $245 \mu \mathrm{g} \cdot \mathrm{g}^{-1}$ em agosto/98 e o máximo de 748 $\mu \mathrm{g} . \mathrm{g}^{-1}$ na coleta imediatamente posterior (Fig. 3b). O mesmo foi observado para Gymnogongrus sp coletada em Barra do Furado, cujas concentrações variaram de 398 $\mu g . g^{-1}$ em julho 1998 a 3566 $\mu g^{-1}{ }^{-1}$ em Março 1999. Já a concentração de Fe em Gymnogongrus sp na praia de Ponta do Retiro, não variou significativamente durante o período amostral, assim como para $U$. fasciata em Barra do Furado.

A concentração de $Z n$ variou significativamente $(p<0,05)$ ao longo do período amostral em ambas as macroalgas na praia de Barra do Furado (Fig. 3a). Evidencia-se, também para este mesmo metal, que as espécies estudadas não possuem a mesma capacidade de concentrá-lo em seus tecidos. Tal fato é mais evidente se observarmos que a maior concentração determinada para a clorófita, correspondeu aos menores valores para a rodófita $\left(11,6 \mu g \cdot g^{-1}\right)$. Já a concentração de Cu não variou significativamente em nenhuma das praias estudadas.

\section{DISCUSSÃo}

É consenso entre diversos autores, que algas marinhas pertencentes ao grupo das algas vermelhas, rodófitas, tendem a apresentar concentrações superiores de metais pesados quando comparadas às algas verdes, clorófitas, (LOBBAN, 1985; LACERDA, 1992). De uma forma geral, esta hipótese pôde ser confirmada no presente estudo para todos os metais, independente do local em que as amostras foram coletadas. As concentrações de $\mathrm{Cr}\left(3,0 \mu \mathrm{g} \cdot \mathrm{g}^{-1}\right), \mathrm{Cu}\left(4,1 \mu \mathrm{g} \cdot \mathrm{g}^{-1}\right)$, Fe $\left(1087 \mu \mathrm{g} \cdot \mathrm{g}^{-1}\right), \mathrm{Mn}$ $\left(243,5 \mu \mathrm{g} \cdot \mathrm{g}^{-1}\right)$ e Zn $\left(32 \mu \mathrm{g} \cdot \mathrm{g}^{-1}\right)$ em Gymnogongrus $s p$ foram em média, maiores que em Ulva fasciata $\left(0,9 \mu \mathrm{g} . \mathrm{g}^{-1} ; 2,9 \mu \mathrm{g} \cdot \mathrm{g}^{-1} ; 394 \mu \mathrm{g} \cdot \mathrm{g}^{-1} ; 9,9 \mu \mathrm{g} \cdot \mathrm{g}^{-1} ; 6,4 \mu \mathrm{g} \cdot \mathrm{g}^{-1}\right.$ respectivamente para $\mathrm{Cr}, \mathrm{Cu}, \mathrm{Fe}, \mathrm{Mn}$ e Zn). Segundo Estevez et al. (2002) algas vermelhas, como as do gênero Gymnogongrus, possuem grupos polissacarídicos, como as carragenanas, ligados à parede celular do vegetal. Wahbeh (1985) cita que estes compostos possuem elevada afinidade por elementos metálicos em função de suas cargas e pela estabilidade de suas ligações com metais pesados. Além destes aspectos, nota-se que as algas possuem aspectos morfológicos bastante diferentes: enquanto U. fasciata possui uma aparência lamelar, Gymnogongrus sp tende a formar tufos, aumentando sua área de superfície. Estes aspectos morfológicos

Tropical Oceanography, Recife: v. 31, n. 1, p. 71-80, 2003 
distintos foram descritos por Sawidis et al. (2001) como responsáveis por diferenças de concentração de metais pesados em diferentes espécies de algas marinhas. Villares et al. (2002) citam que variações morfológicas entre diferentes espécies de algas podem favorecer a contaminação por metais a partir do material particulado em suspensão.

Os resultados obtidos no presente estudo, quando comparados com aqueles descritos na literatura (Tabela 1), mostram que as concentrações de Cr, Cu e Zn estão próximas a áreas descritas como naturais ou levemente impactadas por metais pesados.

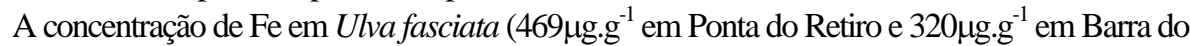

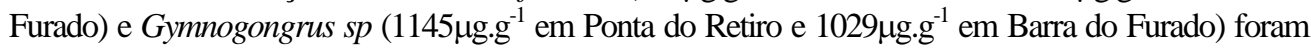
mais elevadas que aquelas de áreas descritas como contaminadas (Tabela 1).

Storelli et al. (2001) relatam concentrações similares de Fe (média de 337 $\mu \mathrm{g} . \mathrm{g}^{-1}$ ) em Ulva lactuca na costa italiana. Os mesmos afirmam que macroalgas marinhas necessitam acumular Fe para seu crescimento normal, tendo ainda a capacidade de bioacumular este elemento a partir do meio, principalmente quando sua abundância no ambiente é elevada. Elevadas concentrações deste elemento também foram descritos por Ferreira (2000) para o mexilhão Perna perna nestas mesmas praias, com concentrações médias de Fe de $1130 \mu \mathrm{g} \cdot \mathrm{g}^{-1}$ de peso seco. O autor cita o material particulado em suspensão e o substrato composto por concreções ferruginosas (PEDRINI, 1984) como as principais fontes de Fe para incorporação pela biota nesta região. De fato, além da fração dissolvida, a geologia do local e, conseqüentemente o substrato de fixação, podem contribuir na transferência de metais pesados para macroalgas marinhas, conforme descrito por Sawidis et al (2001).

Além disso, é sabido que o sedimento e o material constituído por partículas em suspensão, representam os principais reservatórios que regulam a concentração dos elementos na fração dissolvida e desta para as algas marinhas (AMADO-FILHO et al 1997). Resultados de Carvalho et al (2002) apontam para a elevada capacidade de exportação de Fe e Mn ligado ao material particulado em suspensão do continente para o ambiente marinho através de transporte fluvial no Norte do Estado do Rio de Janeiro, tendo como seu principal representante o rio Paraíba do Sul. Estes dados confirmam as elevadas concentrações de Fe determinadas em ambas as espécies de macroalgas marinhas no presente estudo.

A concentração de Mn em Gymnogongrus sp, especificamente em Barra do Furado (média de $453 \mu \mathrm{g} . \mathrm{g}^{-1}$ ), também se situou acima da média descrita na literatura, até mesmo para áreas contaminadas por metais pesados. Ferreira (2000), ao determinar a concentração

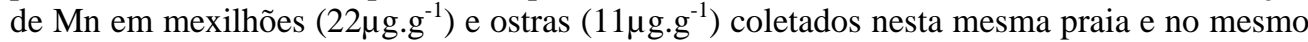
período, não constatou valores elevados deste metal ao comparar seus resultados com os de bivalves de outros estudos. Como ambos os bivalves são filtradores de partículas presentes na fração particulada em suspensão, podemos sugerir que o Mn em Barra do Furado estaria principalmente biodisponível a partir da fração dissolvida. Presumivelmente, este Mn seria proveniente de áreas alagáveis composta de solos orgânicos originados a partir de depósitos de matéria vegetal em diferentes estágios de decomposição (CIDE, 1997). Durante o período das chuvas, estas regiões marginais ao Canal das Flechas, estariam atuando como exportadoras deste metal na forma reduzida, portanto em solução, para o ambiente marinho.

Rezende et al (1997a), em estudo anteriormente realizado nas praias de Ponta do Retiro e Barra do Furado, constataram que o Mn acumulou-se preferencialmente na rodófita Gymnogongrus griffithsiae e o zinco na clorófita Ulva fasciata. Os autores ainda citam que o único elemento cuja concentração variou entre as duas espécies em cada local foi o Fe. Nossos resultados, diferentemente destes, apontam que a rodófita Gymnogongrus sp apresentou maiores concentrações não só de Mn, mas também de Fe e Zn, quando comparada com a clorófita $U$. fasciata,

O Cu é considerado um dos metais mais tóxicos para macroalgas (LOBBAN, 1985). O mesmo autor cita que este metal é capaz de afetar a permeabilidade do plasmalema, causando a perda de $\mathrm{K}^{+}$pela célula algal. Ele pode ainda ser transportado para o citoplasma e então para os cloroplastos, onde haverá a inibição da fotossíntese pelo desacoplamento dos elétrons da cadeia transportadora. No presente estudo,

Tropical Oceanography, Recife: v. 31, n. 1, p. 71-80, 2003 
foram determinadas em $U$. fasciata de ambos os locais, concentrações médias de Cu de 3,0 $\mu g . g^{-1}$ (Fig. 2). Gymnogongrus sp apresentou concentrações próximas a da clorófita (média de 4,1 $\mu \mathrm{g} \cdot \mathrm{g}^{-1}$ ). Relatos da literatura (Tab. 1) mostram concentrações similares para áreas não impactadas por metais pesados. Considerando-se que a presença deste metal em elevadas concentrações nos organismos está comumente associada a esgotos domésticos, podemos dizer que os valores de $\mathrm{Cu}$ determinados em ambos os locais refletem apenas os níveis de base para a região, facilmente metabolizados pelas algas.

\section{Variação Espacial: Barra do Furado vs Ponta do Retiro.}

As concentrações de todos os metais variaram significativamente $(\mathrm{p}<0,05)$ entre as praias para a clorófita $U$. fasciata. Fe, Cu e Mn acumularam-se preferencialmente nas amostras coletadas em Ponta do Retiro (Fig. 1). Cr e Zn (Fig. 1) apresentaram maiores concentrações em Barra do Furado. Resultados semelhantes foram obtidos por Ferreira (2000), que relata maiores concentrações de Cr e Zn em mexilhões e ostras coletados em Barra do Furado quando comparadas a amostras obtidas em Ponta do Retiro. Tal fato indicaria que a disponibilidade destes metais para incorporação tanto pelos organismos filtradores, quanto para as algas, necessariamente tem na fração dissolvida, uma importante contribuição.

A rodófita Gymnogongrus sp acumulou significativamente $(\mathrm{p}<0,05)$ mais $\mathrm{Cu}$ e Mn na praia de Barra do Furado do que em Ponta do Retiro (Fig. 2 e 4).

No presente estudo, as concentrações de Cu em Gymnogongrus sp na praia de Barra do Furado

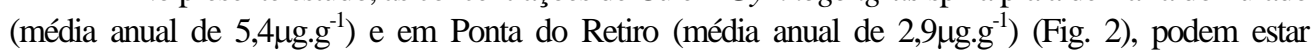
associadas a problemas sanitários como despejos domésticos, também discutidos por Pfeiffer et al. (1985) e por Rezende e Lacerda (1986) como os principais exportadores destes metais para o meio ambiente marinho.

\section{Variação Temporal: Barra do Furado e Ponta do Retiro.}

Concentrações reduzidas de Cr em ambas as macroalgas (<0,1 $\left(\mu\right.$ g.g -1) $^{-1)}$ de Zn em U. fasciata (< 0,3 $\mu \mathrm{g} . \mathrm{g}^{-1}$ ) entre outubro 1998 e fevereiro 1999 nas duas praias, podem indicar redução na disponibilidade destes metais na fração dissolvida neste período. Segundo dados pluviométricos citados por Ferreira (2000), ocorreu um aumento das chuvas na região. De acordo com Carvalho (1999), o aumento da vazão fluvial provocada pelas chuvas pode contribuir para uma diluição na concentração de metais e conseqüentemente para uma diminuição na biodisponibilidade destes metais no meio ambiente aquático.

Em Barra do Furado foram determinadas elevadas concentrações de Mn ao longo de todo período amostral, com uma nítida tendência de acúmulo no final do verão, período de maior pluviosidade na região. Gledhill et al. (1998) citam que certos metais pesados como Fe e Mn, normalmente ligados a matriz mineralógica, tendem a aderir ao tecido vegetal de macroalgas na forma de materiais biogênicos (microalgas e bactérias) e partículas terrígenas, o que pode explicar as variações temporais observadas em nosso estudo para o Mn.

Acredita-se que a concentração de Fe em Gymnogongrus sp na praia de Ponta do Retiro não varie significativamente ao longo do tempo, possivelmente devido à geologia do local. Isto se deve ao fato de que o substrato consolidado em que foram coletadas as macroalgas, apresenta concreções ferruginosas que podem ser uma fonte constante deste metal para estes organismos (PEDRINI, 1984). Lacerda (1992) cita que apesar das algas marinhas bentônicas incorporarem preferencialmente metais da fração dissolvida, em situações específicas elas podem responder a variação da concentração destes metais no sedimento (Tab. I).

Não houve variação significativa na concentração de $\mathrm{Cu}$ ao longo do ano nas duas praias, o que pode estar evidenciando um recrutamento anual homogêneo ou um rígido controle metabólico deste metal por esta clorófita.

Existem diferentes fatores que justificam as variações temporais encontradas. Villares et al.. (2002) relatam fatores ambientais (variação na concentração dos metais em solução, interações entre 
metais e outros elementos, salinidade, $\mathrm{pH}$ ); fatores metabólicos (diluição na concentração dos metais devido ao crescimento da planta); ou interação entre ambos os tipos de fatores.

Os resultados obtidos indicam que Gymnogongrus sp seria a espécie mais recomendada para o monitoramento de cromo, cobre, ferro, manganês e zinco na fração dissolvida em Ponta do Retiro e Barra do Furado, não só por possuir vasta distribuição nos locais amostrados, ser de fácil coleta e séssil, mas principalmente por possuir maior capacidade para concentrar estes metais.

Para um melhor entendimento do aporte de metais pesados das águas continentais para o mar, são necessários estudos sobre a concentração de metais no material particulado em suspensão e no sedimento destes locais. A determinação de metais pesados na fração dissolvida também forneceria uma valiosa contribuição para a interpretação dos resultados encontrados, apesar da dificuldade analítica de determinação destes valores na água do mar.

Em Barra do Furado, apesar de Gymnogongrus sp ter apresentado concentrações superiores de todos os metais em relação à $U$. fasciata, deveriam ser realizados estudos mais aprofundados, principalmente quanto a possível influência exercida pelo Canal das Flechas. Podemos concluir que:

I) As praias de Ponta do Retiro e Barra do Furado podem ser classificadas como naturais ou levemente poluídas, para as concentrações de cromo, cobre, ferro, manganês e zinco na rodófita Gymnogongrus sp e na clorófita Ulva fasciata;

II) Com relação à variação espacial, as concentrações de cromo, cobre e manganês foram superiores na praia de Barra do Furado, enquanto as concentrações de ferro e zinco foram mais elevadas em Ponta do Retiro;

III) Com relação à variação temporal, as concentrações de cromo (nos dois locais e ambas as macroalgas), ferro (na rodófita de Barra do Furado e na clorófita de Ponta do Retiro), manganês (exceto na clorófita em Ponta do Retiro) e zinco (exceto na rodófita em Ponta do Retiro), variaram significativamente ao longo do ano amostral. Maiores concentrações de ferro e manganês ocorreram de fevereiro 1999 a maio 1999 enquanto menores valores de cromo e zinco foram registrados em outubro e novembro 1998;

IV) As maiores concentrações de metais foram observadas em Gymnogongrus sp em ambas as praias, à exceção do cobre nas amostras coletadas em Ponta do Retiro. Desta forma, recomenda-se a rodófita Gymnogongrus sp para o monitoramento de cromo, cobre, ferro, manganês e zinco na fração dissolvida nas praias de Barra do Furado e Ponta do Retiro.

\section{REFERÊNCIAS}

AMADO-FILHO, G. M.; ANDRADE, L R.; REIS, R. P.; BASTOS, W.; PFEIFFER, W. C., Heavy metal concentrations in seaweed species from the abrolhos reef region, Brazil.. Proc 8th Int Coral Reef Sym, v. 2, p. 1843-1846. 1997.

CARVALHO, C. E. V.; LACERDA, L. D. heavy Metals in the Guanabara Bay biota: Why such low concentrations? Ciênc. Cult., v. 44, n. 2/3, p. 184-186. 1992.

CARVALHO, C. E. V.; LACERDA, L. D.; GOMES, M. P. Metais pesados na biota da Baía de Sepetiba e Angra dos Reis, RJ. Acta Limnol. Brasil., v. 6, p. 222-229. 1993.

CARVALHO, C. E. V. Seasonal variaton of particulate heavy metals in the lower Paraíba do Sul River, RJ., Brazil. Environ. Geol. v. 37, p. 297-302. 1999 
CARVALHO, C. E. V.; CAVALCANTE, M. P. O.; GOMES, M. P.; FARIA, V. V.; REZENDE, C. E. Distribuição de Metais Pesados em Mexilhões (Perna perna) da Ilha de Santana, Macaé, SE, Brasil.

Ecotox. and Environ. Rest.. v. 4m n. 1. 2001

CARVALHO, C. E. V.; SALOMÃO, M. S. M. B.; MOLISANI, M. M.; REZENDE, C. E.;

LACERDA, L. D. Sci. To. Environ.. 284 p. 85-93. 2002.

CIDE - Centro de Informação e Dados do Rio de Janeiro. Estado do Rio de Janeiro: Território.

Relatório. 1997 80p.

ESTEVEZ, J. M.; CIANCIA, M.; CEREZO, A. S. Carrageenans biosynthesized by carposporophytes of red seaweeds Gigartina skottsbergii (Gigartinacea) and Gymnogongrus torulosus (Phyllophoracea). J.

Phycol.v. 38:, p. 344-350. 2002

GLEDHILL et al. Comparison of Techniques for the Removal of Particulste Material from Seaweeds

Tissue. Mar. Environ. Res.. v. 45, n. 3, p. 295-307. 1998.

GUIMARÃES, J. R. D.; LACERDA, L. D.; TEIXEIRA, V. L., Concentração de metais pesados em algas bentônicas da Baía do Ribeira, Angra dos Reis, com sugestão de espécies monitoras. Revista Brasileira Biologia, v. 42, n. 3. p. 553-557. 1982

FERREIRA, A. G. Metais Pesados em Moluscos Bivalves no Litoral Norte do Estado do Rio de Janeiro, Brasil. Rio de Janieor, 2000. 83f. Dissertação (Mestrado) - Universidade Estadual do Norte Fluminense.

KAREZ, C. S; MAGALHÃES, V. f; PFEIFFER, W. C.; AMADO FILHO, G. M. Trace metals accumulation by algae in Sepetiba Bay, Brazil. Environ. Poll., v. 83, p. 351-356, 1994a.

KAREZ, C. S; AMADO FILHO, G. M; MOLL, D. M; PFEIFFER, W. C Concentração de Metais em Algas Marinhas Bentônicas de Três Regiões do Estado do Rio de Janeiro. An. Acad. Bras. Ci,ência, v. 66, n. 22, p. 205-211. 1994b.

LACERDA, L. D. The Behavior of Trace Metals in Benthic Marine Algae. In: CORDEIRO-MARINO, M.; AZEVEDO, M. T. P.; SANT'ANNA, C. L.; TOMITA, N. Y.; PLASTINO, E. M. (ed). Algae and Environment: A General Approach. Soc. Brasil. Ficol., São Paulo, 1992, p. 99-108.

LOBBAN, C. S; HARRISON, P. J.; DUNCAN, M. J. The Physiological Ecology of Seaweeds. Cambridge University Press, Cambridge, 1985. p. 135-140.

MINISTÉRIO DA MARINHA DO BRASIL. 1 . Relatório Sobre as Análises dos

Poluentes Realizadas em 1996/1997. Projeto de Monitoramento do Meio Ambiente Marinho. Instituto de Estudos do Mar Almirante Paulo Moreira. 1997. 82p.

PEDRINI, A. G. Algas marinhas do Litoral Norte-Fluminense. At. Soc. Bot. Brasil. v. 2, n. 17, p. 133141. 1984.

PFEIFFER, W. C.; LACERDA, L. D.; FISZMAN, M.; LIMA, N. J. W. Metais Pesados No Pescado Da Baía De Sepetiba, Estado Do Rio De Janeiro. Ciênc. Cult.. v. 37. n. 2, p. 297302. 1985.

REZENDE, C. E.; LACERDA, L. D. Metais pesados em mexilhões Perna perna no litoral do estado do Rio de Janeiro. Rev. Brasil. Biol., v. 46, p. 239-247. 1986. 
REZENDE, C. E.; ZALMON, I. R.; HADDAD, C. Metais pesados em Macroalgas Marinhas da Costa Norte do estado do Rio de Janeiro. Anais VII Congr. Lat. Amer. Ciências Del Mar, p. 340-342. 1997a

REZENDE, C. E.; ZALMON, I. R.; FERNANDES, F. C.; FARIA, V. V.; GOMES, M. P. Metais pesados em Macroalgas Marinhas e Bivalves em Arraial do Cabo, RJ. Anais VII Congr. Lat. Amer. Ciências Del Mar, p. 338-340. 1997b.

SANTOS, D. O. Distribuição de Elementos Maiores e Menores e Traços na Fração Potencialmente Biodisponível ao Redor de Duas Plataformas de Produção de Petróleo, Pampo e Pargo, na Bacia de Campos Rio de Janeiro, 2001, 86f. Monografia. Universidade Estadual do Norte Fluminense.

SAWIDIS, T.; BROWN, M.T.; ZACHARIADIS, G.; SRATIS, I. Trace Metal Concentrations in Marine Macroalgae from Different Biotopes in the Aegean Sea. Environ. Intern. n. (23), p. 43-47. 2001.

STORELLI, M. M.; STORELLI, A.; MARCOTRIGIANO, G. O. Heavy Metals in the aquatic environmental of the Southern Adriatic Sea, Italy Macroalgae, Sediments and Benthic Species. Environ. Intern. v. 26, p. 505-509. 2001.

VILLARES, R.; PUENTE, X.; CARBALLEIRA, A. Seazonal Variation and Background Levels of Heavy Metals in Two Green Seaweeds. Environ. Poll., v. 119. p. 79-90. 2002

WAHBEB, M. I. Concentrations of $\mathrm{Zn}, \mathrm{Mn}, \mathrm{Cu}, \mathrm{Cd}, \mathrm{Mg}$ and Fe in tem species of algae and seawater from Aqaba, Jordan. Mar. Environ. Res.. n. 16. p. 95-1021985

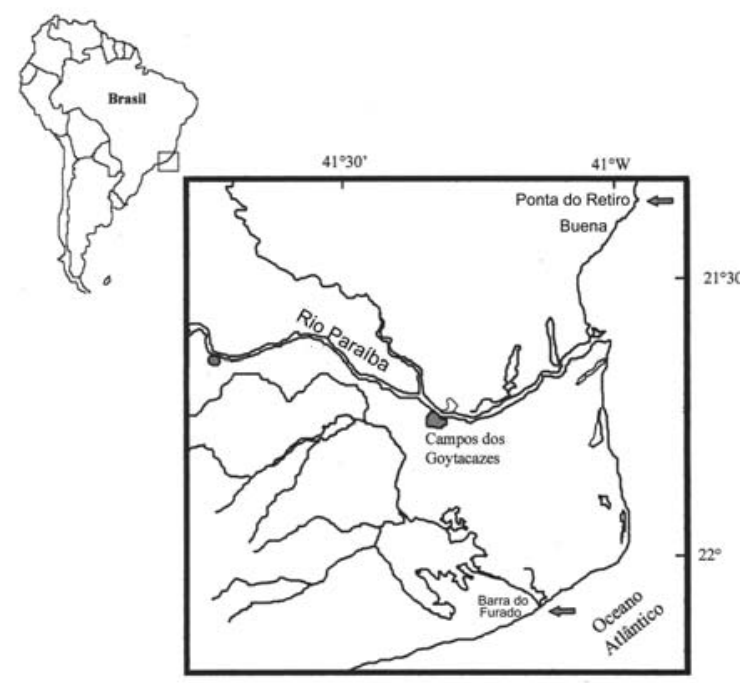

Figura 1 - Mapa da área de estudo no norte do estado do Rio de Janeiro, com a indicação dos pontos de coleta (setas): praia de Ponta do Retiro $\left(21^{\circ} 29^{\prime} \mathrm{S} ; 40^{\circ}\right.$ $\left.59^{\prime} \mathrm{W}\right)$; praia de Barra do Furado $\left(22^{\circ}\right.$ $\left.\mathrm{S} ; 41^{\circ} \mathrm{W}\right)$. 

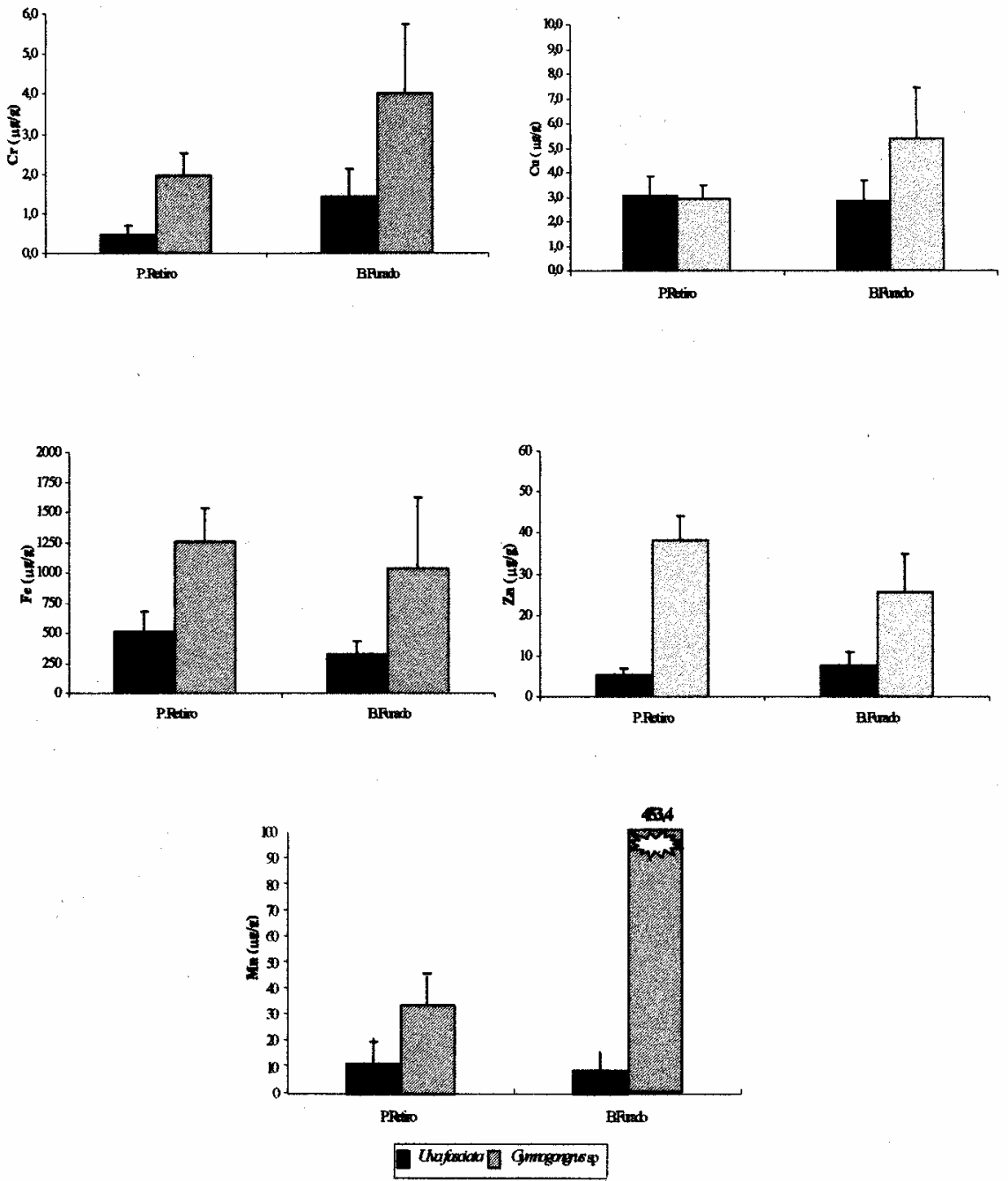

Figura 2 - Valor médio anual das concentrações de cromo, cobre, ferro manganês e zinco em U. fasciata e Gymnogongrus sp nos dois locais de coleta. 
80

Tabela 1 - Valores médios das concentrações de $\mathrm{Cr}$, $\mathrm{Cu}$, Fe, Mn e Zn em macroalgas nas áreas de estudo e em outras áreas tropicais e temperadas (valores em g.g ${ }^{-1}$ de peso seco).

REGIÃO-ESPÉCIE CR CU FE MN ZN REFERÊNCIAS

\section{Ponta do Retiro}

$\begin{array}{llcccccc}\S & \text { Gymnogongrus sp } & \mathbf{2 , 0} & \mathbf{2 , 9} & \mathbf{1 1 4 5} & \mathbf{3 4} & \mathbf{3 8} & \text { Presente Estudo } \\ \dagger & \text { Ulva fasciata } & \mathbf{0 , 5} & \mathbf{3 , 1} & \mathbf{4 6 9} & \mathbf{1 1} & \mathbf{5 , 3} & \text { Presente Estudo } \\ \S & \text { Gymnogongrus sp } & \mathbf{4 , 0} & \mathbf{5 , 4} & \mathbf{1 0 2 9} & \mathbf{4 5 3} & \mathbf{2 6} & \text { Presente Estudo } \\ \dagger & \text { Ulva fasciata } & \mathbf{1 , 4} & \mathbf{2 , 8} & \mathbf{3 2 0} & \mathbf{8 , 8} & \mathbf{7 , 6} & \text { Presente Estudo }\end{array}$

\begin{tabular}{|c|c|c|c|c|c|c|c|}
\hline & Ponta do Retiro & & & & & & \\
\hline$\S$ & Gymnogongrus griffithsiae & - & - & 337 & 91 & 16 & Rezende et al. (1997a) \\
\hline \multirow[t]{2}{*}{$\dagger$} & Ulva fasciata & - & - & 285 & 39 & 23 & Rezende et al. (1997a) \\
\hline & Barra do Furado & & & & & & \\
\hline$\S$ & Gymnogongrus griffithsiae & - & - & 399 & 113 & 14 & Rezende et al. (1997a) \\
\hline \multirow[t]{2}{*}{$\dagger$} & Ulva fasciata & - & - & 464 & 42 & 30 & Rezende et al. (1997a) \\
\hline & Baía de Guanabara & & & & & & \\
\hline$\dagger$ & Ulva fasciata & - & 8,0 & - & 10 & 1,3 & Carvalho \& Lacerda (1992) \\
\hline \multirow[t]{2}{*}{$\dagger$} & Ulva fasciata & - & 8,0 & - & 78 & 27 & Carvalho \& Lacerda (1992) \\
\hline & Baía de Sepetiba & & & & & & \\
\hline$\dagger$ & Ulva fasciata & - & 3,0 & - & 44 & 19 & Carvalho et al. (1993) \\
\hline$\S$ & Acanthophora spicifera & 1,8 & 5,2 & - & - & 103 & Karez et al. (1994a) \\
\hline \multirow[t]{2}{*}{$\dagger$} & Ulva fasciata & 1,1 & 4,0 & - & - & 43 & Karez et al. (1994a) \\
\hline & Baía da Ribeira & & & & & & \\
\hline$\S$ & Acanthophora spicifera & - & 9,9 & - & - & 30 & Karez et al. (1994b) \\
\hline$\S$ & Acanthophora spicifera & 5,5 & 5,2 & - & 30 & 20 & Guimarães et al. (1982) \\
\hline \multirow[t]{2}{*}{$\dagger$} & Caulerpa racemosa & 7,9 & 5,2 & - & 51 & 21 & Guimarães et al. (1982) \\
\hline & Angra dos Reis & & & & & & \\
\hline$\S$ & Asparagopsis sp & - & 9,5 & - & 93 & 46 & Carvalho et al. (1993) \\
\hline \multirow[t]{2}{*}{$\dagger$} & Ulva fasciata & - & 6,6 & - & 18 & 6,4 & Carvalho et al. (1993) \\
\hline & Arraial do Cabo & & & & & & \\
\hline$\dagger$ & Ulva fasciata (Prainha) & $<0,2$ & 3,5 & 179 & 5,5 & 5,9 & Rezende et al. (1997b) \\
\hline$\dagger$ & Ulva fasciata (P. Anjos) & $<0,2$ & 3,4 & 244 & 9,5 & 8,7 & Rezende et al. (1997b) \\
\hline
\end{tabular}

Obs: † - Clorófita $\S$ - Rodófita 